\title{
A Utility Account of Liberal Education
}

\author{
Jane Gatley \\ University of Birmingham
}

\section{INTRODUCTION}

Western schooling has been dominated by some form of broad theoretical education since classical times; this sort of education has traditionally been termed a "liberal education." Providing a coherent account of why a broad theoretical education is worthwhile is an important project given the pervasiveness of this model of education. One common account of the value of liberal education links a broad theoretical education with the intrinsic value of the knowledge transmitted. In this paper, I offer a different, utility-based account of the value of liberal education.

I outline reasons for thinking that an account of liberal education which rests on the intrinsic value of knowledge is problematic. In response, I present a utility account of liberal education which holds that a liberal education is justified insofar as it helps people to interact effectively with the world. Intrinsic value of knowledge accounts of liberal education acknowledge the utility of a theoretical education, but see it as incidental. I cast the utility of a theoretical education as central. This proposed utility account of liberal education provides a useful framework for discussing liberal education and the liberal curriculum.

\section{LIBERAL EDUCATION AS A DESCRIPTIVE TERM}

Teasing apart normative accounts of liberal education from descriptive accounts is an important preliminary step in providing an account of the aims of a liberal education. Liberal education, as a descriptive term, has been associated with curricula which provide a broad theoretical education since at least classical times.

Athenian students over the age of fourteen were taught "a voluntary course of higher studies, chiefly mathematics (i.e., arithmetic, geometry, and astronomy) and rhetoric, and sometimes including literature, art, dialectic, geography, prosody, logic, philosophy, and political science."2 Cicero describes a 
Roman education in geometry, music, literature and poetry, natural sciences, the study of peoples, and the study of the State. ${ }^{3}$ After the fall of the Roman empire the seven liberal arts, consisting of grammar, rhetoric, logic, arithmetic, geometry, astronomy, and music, dominated schooling. ${ }^{4}$ Today, the English National Curriculum lists English, mathematics, science, art and design, citizenship, computing, design and technology, geography, history, languages, music, and physical education as requirements for secondary education. ${ }^{5}$

The reason for listing these curricula is to draw attention to their similarities. They each cover a broad range of activities, focus on theoretical (know-that) rather than practical (know-how) learning, and reflect something of the best available ideas of the time. This sort of education, which introduces students to a broad and balanced range of theoretical activities selected from the best available to humankind, has traditionally been called a liberal education.

Given the prevalence of this model of education across the world, having an account of why a broad theoretical liberal education might be worthwhile is important. If it is possible to identify justifiable aims of a broad theoretical education, then it is possible to make judgements about whether a broad theoretical liberal education is worthwhile, how much school time ought to be spent on liberal education, and what a liberal curriculum ought to look like. This is why a philosophical conception of liberal education is needed.

\section{THE INTRINSIC VALUE OF A LIBERAL EDUCATION}

One account of the value of providing students with a broad theoretical education is that it is equivalent to providing students with knowledge, and that providing knowledge is worthwhile since knowledge is intrinsically valuable. This account of the value of liberal education is so widespread that it is sometimes taken as definitive: "Liberal education attempts to teach the most worthy knowledge and texts, as well as to provide models of how to acquire knowledge and to nurture the intellectual virtues that promote that acquisition." The tendency to equate the idea of a liberal education with the transmission of knowledge is why recalling the use of 'liberal education' as 
a descriptive term is important; the fact that some see liberal education as synonymous with the transmission of knowledge does not mean that this is the only way in which liberal education can be conceptualised. There could be other reasons for providing students with a broad theoretical education.

The view that a liberal education aims to provide knowledge has pedigree. Plato's concept of liberal education rests on the intrinsic value of knowledge, possession of which is a component of the good life. Hirst develops an account such that a liberal education is "an education based on the nature of knowledge itself." Newman agrees that "knowledge is capable of being its own end" and uses this to justify providing a broad theoretical education in universities. ${ }^{8}$ O'Hear asserts that "the disciplines are taught and engaged in for their own sake, because they are recognised to be valuable in their own right and part of any fully civilised existence."

This intrinsic value of knowledge account of liberal education is appealing because it provides a straightforward explanation for why a broad theoretical education might be worthwhile: it is worthwhile because it is primarily concerned with transmission of knowledge, and knowledge is intrinsically worthwhile. If, as Hirst suggests, it is possible to identify a determinate number of distinct forms of knowledge, then curriculum guidelines begin to emerge such that a liberal education is an education which inducts students into each of these forms of knowledge. The intrinsic value of knowledge account of liberal education yields answers to important questions such as how to plan the curriculum.

\section{PROBLEMS WITH THE INTRINSIC VALUE OF KNOWLEDGE AC- COUNT}

Despite its initial appeal, the intrinsic value account of liberal education is problematic. First, even if knowledge is intrinsically worthwhile, knowledge-based activities are not the only intrinsically worthwhile activities which could be included on the curriculum. Second, the intrinsic value of an activity does not necessarily equate to educational value. Third, some instrumentally valuable activities have clear educational value, and so are in competition with intrinsically valuable activities such as knowledge acquisition for 
curriculum time. Together, these three problems demonstrate that intrinsic value accounts of liberal education do not justify delivering a broad theoretical education.

One argument for the intrinsic value of knowledge is Peters' transcendental argument. This argument asserts that anyone who is concerned with making any correct decision is thereby also concerned with the pursuit of truth. Peters explains that asking "'why do this rather than that?' seriously is... to be committed to those enquiries which are defined by their serious concern with these aspects of reality which give context to the argument he is asking." ${ }^{\prime 0}$ The activities that he has in mind are activities concerned with the pursuit of truth. His claim is that education, which provides guidance about decision making, is primarily concerned with truth, and so pursuing truth through theoretical activities is always educational.

White points out that Peters' transcendental argument fails to countenance the idea that the pursuit of truth is not the only intrinsically, or educationally valuable pursuit. He asks, "Is there any compelling reason why I should value art or science rather than spend my days in a snooker parlour or by the side of a trout stream?"11 Asking "why do this rather than that" may not amount to a commitment to truth; "Suppose a man with a knowledge of the arts and sciences decides to jettison any interest he had in them in favour of a life of idleness and comfort: can it be proved to him that he is somehow irrational, that rationality demands that in his own interests he takes the other course?"12 Spending time in a snooker parlour, by the side of a trout stream, or in idleness and comfort are not instrumentally valuable activities; if they hold any value at all, which they clearly do for some people, then that value is intrinsic. If there are intrinsically valuable pursuits other than the pursuit of knowledge, then why isn't a liberal education also an education into trout fishing, snooker, and idleness? White says that there are no valid arguments to this end.

The second problem with basing a conception of liberal education on the intrinsic value of knowledge is that intrinsic value does not guarantee educational value. Like trout fishing, snooker, and idleness, there are activities which hold intrinsic value but are not ready contenders for inclusion on the 
curriculum. While there is general agreement that viewing original works of art is intrinsically worthwhile to the extent that this motivates the provision of free art galleries in the United Kingdom, there is no such consensus that viewing original works of art ought to take up curriculum time. Schools might be obliged to introduce students to the possibility of viewing original art works, but it does not seem particularly educational to spend much school time engaged in this activity. Similarly, romantic love is, if anything, intrinsically worthwhile, but encouraging romantic love in schools does not seem like an educational activity.

The third problem is that while there are intrinsically worthwhile pursuits which are not educational, there are also instrumentally valuable pursuits which clearly are. Learning to read is only valuable insofar as it provides access to other educational goods; it is instrumentally worthwhile. At the same time, a curriculum which neglects teaching children how to read is profoundly non-educational. Vocational education, relationships education, substance abuse education, even learning how to tie shoelaces, are all instrumentally valuable. Yet, it is possible to argue that they ought to be part of a school curriculum precisely in virtue of this instrumental value.

Together, this means that the intrinsic value of knowledge does not provide a secure foundation for prescribing a curriculum primarily focused on knowledge. This is because even if knowledge is intrinsically valuable, it is not necessarily educationally valuable, or the best contender for curriculum inclusion. Some other account of why a broad theoretical education might be worthwhile is required.

\section{THE UTILITY OF A BROAD THEORETICAL EDUCATION}

The problems with intrinsic value of knowledge accounts of liberal education do not mean that the idea of a liberal education ought to be abandoned. This would leave the widespread practice of providing students with a broad theoretical education unaccounted for. Instead, the task is to attempt to identify other grounds which might justify liberal education. Many theorists who posit an intrinsic value account of liberal education simultaneously point to its instrumental value, or its utility. This is often cast as incidental, or 
secondary to the intrinsic value of knowledge, but is widely recognized.

Bailey's work on liberal education is most explicit about its instrumental value. He says, "The more fundamental is an aspect of knowledge and understanding... the more general are its applications and the more liberated I am in terms of choices I can make and perspectives I can bring to bear." ${ }^{13}$ For Bailey, a liberal education is instrumentally valuable, not in a piecemeal sense, but "it is precisely its general and fundamental utility that provides part of the justification for a liberal general education." ${ }^{\prime 14}$ However, Bailey sees this instrumental value of liberal education as a necessary consequence of its intrinsic value: "The argument would be that we involve pupils in what is fundamental because fundamental understanding of human experience is intrinsically worthwhile, but in doing this we are necessarily providing pupils with the knowledge and understanding that has the most general relevance and utility for anything they are likely to want to do." ${ }^{15}$

Hirst and Peters also acknowledge instrumental value associated with knowledge. Hirst says that "to acquire knowledge is to learn to see, to experience the world in a way otherwise unknown." ${ }^{16} \mathrm{He}$ argues that a liberal education frees conduct from wrong. ${ }^{17}$ Peters states that theoretical activities "illuminate other areas of life and contribute much to the quality of living... there is an immense amount to know and if it is properly assimilated, it constantly throws light on, widens, and deepens one's view of countless other things." ${ }^{18}$ According to Peters, pursuits such as science, history, literary appreciation, and other theoretical activities "consist largely in the exploration, assessment and illumination of the different facts of life. They thus insensibly change a man's view of the world.... A person who has pursued them systematically develops conceptual schemes and forms of appraisal which transform everything else that he does." ${ }^{\prime 19}$ If having these new ways of seeing the world contributes to quality of living and frees conduct from wrong, then theoretical activities have instrumental value.

Hand suggests that Peters lays out the basis for an instrumental account of the value of theoretical activities. Drawing on the idea that knowledge and understanding of theoretical activities sheds light on and transforms many aspects of experience, Hand proposes that "we should give 
curriculum priority to those worthwhile activities that enhance, enter into, or shed light on all others." ${ }^{20}$ His rationale is that "our task as educators is to prepare children for adult life. We cannot do this by initiating them into the activities that will occupy their time as adults because we do not yet know what those activities will be. Instead, we must try to prepare them in some general way, so their education will be useful to them whatever they choose to do with their lives." ${ }^{21}$ If this is the case, then a broad theoretical education can be justified in virtue of its instrumental value.

A final basis for a utility account of liberal education comes from Thomas Huxley, who presents the following analogy:

Suppose it were perfectly certain that the life and fortune of every one of us would, one day or other, depend upon his winning or losing a game at chess. Don't you think that we should all consider it to be a primary duty to learn at least the names and the moves of the pieces; to have a notion of a gambit, and a keen eye for all the means of giving and getting out of check? Do you not think that we should look with disapprobation amounting to scorn, upon the father who allowed his son, or the state which allowed its members, to grow up without knowing a pawn from a knight?

Yet it is a very plain and elementary truth, that the life, the fortune, and the happiness of everyone one of us, and, more or less, of those who are connected with us, do depend upon our knowing something of the rules of a game infinitely more difficult and complicated than chess. It is a game which has been played for untold ages, every man and woman of us being one of the two players in a game of his or her own. The chess-board is the world, the pieces are the phenomena of the universe, the rules of the game are what we call the laws of nature. The player on the other side is hidden from us. We know that his play is always fair, just, and patient. But also we know to our own cost, that he never overlooks a mistake, or makes the smallest allowance for our ignorance. ${ }^{22}$

For Huxley, a liberal education provides guidance about the rules of the game of life. In this sense, a broad theoretical education has straightfor- 
ward utility. The better informed we are about the world, the better able we are to act effectively within it.

\section{A UTILITY ACCOUNT OF LIBERAL EDUCATION}

Given the possibility of ascribing value to a liberal education in virtue of its instrumental value, an account of the value of liberal education can be given which eschews the idea that the intrinsic value of knowledge is what makes it worthwhile and focuses entirely on its utility. The following is an account of liberal education where its worth lies in its utility.

(1) A broad and balanced theoretical education involves acquiring useful ways of understanding the world;

(2) Useful ways of understanding the world contribute to acting effectively within it;

(3) Acquiring the ability to act effectively within the world justifies a liberal education.

This account explains why a broad theoretical education is worthwhile without the need to refer to the intrinsic value of knowledge, since a theory can be instrumentally valuable without amounting to knowledge.

\section{DIFFERENT WAYS OF SEEING THE WORLD}

On this utility account of liberal education, it is the provision of ways of seeing the world which is worthwhile. Ways of seeing the world are not necessarily bodies of justified, true beliefs or knowledge. It is possible to come to see the world in a way which is radically at odds with reality. Nor are ways of seeing the world reducible to methods of inquiry, or ways of thinking, like the scientific method. Instead, ways of seeing the world can be captured by the term "theory," broadly construed. Talking about theory captures the idea that coming to "know" something changes how someone sees the world. Kuhn describes the strength of the effect of theory change such that "the historian of science might be tempted to exclaim that when paradigms change the world itself changes with them." 23 
A theory, seen as a way of understanding the world, can be implicit in a work of art or literature, explicit as a scientific theory, or fragmented into units of theoretical content, such as lists of facts. What is important is that theories, when they are not fragmented, are inherently meaningful; propositions lie in logical relations with one another, and grasping propositions on their own is not sufficient to grasp the theory. Coming to see the world in a new way is unavoidable if a theory is properly understood.

Elgin differentiates between knowing individual truths and understanding them. The example she uses is the difference between saying "I understand that Athens defeated Persia in the battle of Marathon" and "I understand the Athenian victory over Persia in the battle of Marathon." If understanding is just a case of grasping propositional knowledge, then there is no difference between the two claims. However, Elgin holds that understanding involves grasping "a suitable unified, integrated, coherent body of information." ${ }^{24}$ She continues, "I understand that Athens defeated Persia in the battle of Marathon, because I grasp how the proposition stating the facts fits into, contributes to, and is justified by reference to a more comprehensive understanding that embeds it." 25 Any such "unified, integrated, coherent body of information" is a theory, and any element of that theory is theoretical content. Theoretical content provides ways of seeing the world, and so constitutes the salient unit of curriculum content.

\section{ACTING EFFECTIVELY WITHIN THE WORLD}

Since theories provide ways of seeing the world, they also provide guidance about how to interact with it. A useful theory is one which will contribute to someone's ability to interact effectively with the world. For example, when someone comes to see a plant through the lens of photosynthetic theory, they come to understand how to grow that plant better. Since photosynthetic theory has a long history of guiding effective interaction with plants, the theory is worthwhile in light of its utility.

This means that in a basic way, acquiring theoretical content is liberating because it frees people to effectively interact with the world. This 
freedom to interact effectively with the world is not necessarily instrumental in a piecemeal way. Grasping theories which apply to broad areas of inquiry yields broad effective action. Acquiring theoretical content is the equivalent of becoming informed, and someone who is well-informed has a practical advantage over someone who is uninformed or ill-informed across a range of domains. On this view, a liberal education is a broad and balanced education into the most useful theories available to humankind.

This avoids the need to make claims about the intrinsic value of knowledge. Instead, a broad theoretical curriculum is freeing because being well-informed by the most useful available theoretical content helps people to interact effectively with the world. Curriculum selection ought to be based on judgements about the utility of theories, not judgements based on intrinsic value.

Some ability to distinguish between useful and less useful theories is going to be needed. A precedent exists for making this kind of judgment in literature about what makes a good scientific explanation; for example, good explanations can "explain observable phenomena, cohere with already accepted scientific knowledge, are simple, or unify explanations of different kinds of phenomena." 26 This sort of guidance could be adapted to address the utility of non-scientific theories.

\section{THE ABILITY TO INTERACT EFFECTIVELY WITH THE WORLD JUSTIFIES LIBERAL EDUCATION}

Following Huxley's chess metaphor, acquiring theoretical content is useful if it provides people with an understanding of the world which can guide effective action within it. Theoretical content is freeing because it helps people to deal with the issues that they encounter in their lives. The more theoretical content someone is familiar with, the better equipped they are to deal with the world around them. Being equipped to act effectively in the world involves being able to reflect on and bring about desires, be they simple ones such as growing tomatoes, or complex ones such as considering whether to have children. It seems hard to deny that the capacity to act effec- 
tively in this way is a desirable outcome of education.

Whether or not providing this sort of liberal education is the only, or primary task of schools is a separate question. While a liberal education is justifiable in virtue of its utility, its prominence in schooling will need to be weighed up against other instrumentally valuable activities. Civic, vocational, and flourishing-based aims will need separate consideration. However, on a utility account, liberal education can contribute to these further aims. By this, I mean that if the ultimate aim of education is flourishing, then a liberal education will underpin flourishing because flourishing is difficult without the ability to interact effectively with the world. However, a broad theoretical education might not be the only sort of education required for flourishing.

\section{ADDRESSING QUESTIONS ABOUT THE CURRICULUM USING THE UTILITY ACCOUNT}

Although I have only provided a sketch of a utility account of liberal education, I want to hint at some of the consequences of taking this account seriously. Two criteria emerge from the utility account of liberal education about curriculum content selection: (1) the curriculum ought to address questions which are likely to be prominent and pressing to its students, and (2) the answers to these questions ought to consist of the best available theories. The first criterion follows from the idea that the value of a broad and balanced theoretical education lies in its utility. If this is the case, then the curriculum ought to focus on what is going to be useful to its students. One way of doing this is by considering prominent and pressing questions. The second criterion ensures that the theories taught in response are the most useful available.

Given these two criteria, some understanding of what a liberal curriculum ought to look like emerges. A liberal curriculum does not go into too much depth about theory which is unlikely to play much of a role in students' lives if doing so takes time away from more prominent and pressing questions. For example, this implies that teaching chemistry in great detail, at the expense of addressing prominent and pressing questions about rela- 
tionships, fails to uphold the spirit of a liberal education. An intrinsic value account of liberal education comes to the opposite conclusion: since we have sound knowledge about chemistry, but little knowledge about relationships, a liberal education should teach the sound knowledge about chemistry.

Another interesting feature of the utility account of liberal education is that it creates greater parity between disciplines. On an intrinsic value of knowledge account, disciplines like mathematics and the natural sciences which are considered to have privileged access to knowledge are more valuable. On a utility account, the arts and humanities which touch on pressing issues in ordinary lives such as happiness, coping with bereavement, injustice, love, friendship, and family might be more directly useful to students, and so earn their place on the curriculum in virtue of this. Similarly, while mathematics and the natural sciences might be clearer about what constitutes the best available theory to answer the questions in their domain, humanities and arts subjects have a broader range of theoretical content to draw on. Presenting students with a plurality of theories is one way of countering uncertainty about which theory provides the single most useful way of seeing the issue in question. This is consistent with the idea that grasping a range of useful theories can help to guide action, so long as students are also taught how to navigate the range of ideas they are given.

\section{CONCLUSION}

In conclusion, it is worth taking seriously the idea that a broad theoretical education is valuable insofar as it is useful to students. This utility account of liberal education provides curriculum guidance and justificatory potential for a liberal education which rivals intrinsic value of knowledge accounts of liberal education.

1 Mortimer Adler and Milton Mayer, The Revolution in Education (Chicago: University of Chicago Press, 1958), 19.

2 Donald Attwater, "Athenian Education,” The Irish Monthly 55, no. 645 (1927): 135. 
3 Ethyle Wolfe, "Cicero and the Liberal Arts Tradition in America," Ciceroniana Online 8 (1994): 93-102.

4 H. Parker, "The Seven Liberal Arts," The English Historical Review 5, no. 19 (1890): 417-461.

5 Department for Education, National Curriculum in England: Statutory Guidance (October 2014), https://www.gov.uk/government/publications/ national-curriculum-in-england-secondary-curriculum.

6 Jonathan Adler, "Knowledge, Truth and Learning" in A Companion to the Philosophy of Education, ed. Randall Curren (Oxford: Blackwell Publishing, 2003), 289.

7 Paul Hirst, "Liberal Education and the Nature of Knowledge," in Knowledge and the Curriculum (Abingdon: Routledge, 1974), 30.

8 John Henry Newman, The Idea of a University (Cambridge: At the University Press, 1931), 27.

9 Anthony O'Hear, Education, Society and Human Nature: An Introduction to the Philosophy of Education (London: Routledge and Kegan Paul Ltd., 1981), 4.

10 Richard Stanley Peters, Ethics and Education (London: Routledge and Kegan Paul Ltd., 1966), 164.

11 John White, Towards a Compulsory Curriculum (London: Routledge and Kegan Paul Ltd., 1973), 9.

12 White, Towards a Compulsory Curriculum, 14.

13 Charles Bailey, Beyond the Present and the Particular (London: Routledge and Kegan Paul, 1984), 20.

14 Bailey, Beyond the Present, 28.

15 Bailey, Beyond the Present, 29.

16 Hirst, Liberal Education, 31.

17 Hirst, Liberal Education, 33.

18 Peters, Ethics and Education, 159.

19 Peters, Ethics and Education, 160.

20 Michael Hand, “On the Worthwhileness of Theoretical Activities," Journal of Philosophy of Education 43, no. 1 (2010): 118.

21 Hand, "On the Worthwhileness," 118. 
22 Thomas Huxley, "Liberal Education and Where to Find It," in Collected Essays Volume 3: Science and Education (Cambridge: Cambridge University Press, 1893), 81-82.

23 Thomas Kuhn, The Structure of Scientific Revolutions (Chicago: University of Chicago Press, 1962), 111.

24 Catherine Elgin, "Understanding and the Facts," Philosophical Studies 132, no. 1 (2007): 36 .

25 Elgin, "Understanding and the Facts," 36.

26 Adolfas Mackonis, "Inference to the Best Explanation, Coherence and Other Explanatory Virtues," Synthese 190 (2013): 975. 
